\title{
Influence of graphene and multi-walled carbon nanotube additives on tribological behavior of lubricants
}

Rabesh Kumar Singh*, Amit Rai Dixit, Vimal Mandal

Department of Mechanical Engineering,

Indian Institute of Technology (ISM),

Dhanbad, 826004, India

Email: rasm.singh@gmail.com*

Email: amitraidixit@gmail.com

Email: vimal05.mech@gmail.com

*Corresponding author

Anuj Kumar Sharma

Department of Mechanical Engineering,

Institute of Engineering \&Technology,

SRM University Kattankulathur,

Tamil Nadu, 603203, India

Email: sharmaanuj79@gmail.com

Arun Kumar Tiwari

Department of Mechanical Engineering, Institute of Engineering \&Technology,

Lucknow, 22602, India

Email: arun_tiwari25@yahoo.co.in

Alokesh Pramanik

Department of Mechanical Engineering,

Curtin University, Bentley,

WA, 6102, Australia

Email: alokesh.pramanik@curtin.edu.au

\begin{abstract}
In the present study, the tribological performance of water-based emulsion (lubricant) was investigated by blending carbon fillers such as graphene nanoplatelets and multiwall carbon nanotubes using pin-on-disc tribometer. It was noticed that addition of $\mathrm{GnP}$ and MWCNT in water-based emulsion (conventional lubricant) increases the thermal conductivity and viscosity as compared to conventional lubricants. The nanolubricants were supplied with minimum quantity lubrication (MQL) technique at a constant flow rate and
\end{abstract}


pressure in the sliding zone. The addition of $0.8 \mathrm{wt} . \%$ concentration of $\mathrm{GnP}$ showed $58.39 \%$ reduction in coefficient of friction and $61.80 \%$ reduction in wear depth compared to the conventional lubricant. Similarly, for 0.8 wt.\% concentration of MWCNT showed 26.27\% reduction in coefficient of friction and $47.35 \%$ reduction in wear depth compared to the conventional lubricant. The sliding surface micrographs were also investigated to explain the synergistic effect of nanoparticles.

Keywords: Nanolubricants, Wear depth, Coefficient of friction, MWCNT, $\mathrm{GnP}$

Biographical notes:

Rabesh Kumar Singh received his bachelor's degree (B. Tech.) from UPTU, Lucknow, India and master degree manufacturing engineering in 2014 from the Indian school of mines, Dhanbad, India. Currently he is a Ph.D. student in the Indian Institute of Technology (Indian school of mines) Dhanbad, India at the Department of Mechanical Engineering. His research interests include machining, tribology, nanofluids and nanolubrication.

Amit Rai Dixit received his PhD degree in Production Engineering in 2009 from the MNNIT, Allahabad, India. Currently he is associate professor in the Indian Institute of Technology (Indian school of mines) Dhanbad, India at the Department of Mechanical Engineering. His research interests include Traditional and nontraditional manufacturing, production management, cellular manufacturing, and Composite materials.

Anuj Kumar Sharma received his master degree in Mechanical Engineering in 2008 from Uttar Pradesh Technical University, Lucknow, UP, India and PhD degree in 2017 from Indian Institute of Technology (Indian school of mines) Dhanbad, India. Currently he is assistant professor Department of Mechanical Engineering, SRM Institute of Science and Technology (formerly known as SRM University), Kattakulathur Campus, India. His research interests include Nano-cutting fluids in Machining.

Arun Kumar Tiwari received his master degree in Alternate Hydro Energy system in 2004, from IIT-Roorkee, India and PhD degree in 2013 from Indian Institute of Technology (Banaras Hindu University) Varanasi, India. Currently he is associate professor Department of Mechanical Engineering, Institute of Engineering and Technology, Lucknow, India. His research interests include Heat Transfer, Solar Thermal Energy, Energy Storage, Nanofluids, Thermal Manufacturing, Computational Fluid Dynamics, Electronics Cooling.

Vimal Mandal pursuing his master degree in maintenance and tribology from the Indian school of mines, Dhanbad, India. Currently he is a M Tech. scholar in the Indian Institute of Technology (Indian school of mines) Dhanbad, India at the 
Department of Mechanical Engineering. His research interests include tribology and nanolubrication.

Alokesh Pramanik received his PhD degree. Currently he is Lecturer in Department of Mechanical Engineering, Faculty of Science and Engineering, Curtin University, Bentley, Perth, WA, Australia. His research interests include Machining processes and composite material.

\section{Introduction}

Friction and wear are the natural phenomena if two mating bodies have relative motion between them. In the industry, most of the machinery parts have relative motion between them which generates heat due to friction and wear. As a result, it degrades the life of moving parts. The contact between two sliding materials leads to the loss of material that deteriorates the dimensional accuracy and performance (Lin et al., 2015). The higher values of coefficient of friction can generate more wear and consumes a large amount of energy in moving parts, which reduces the efficiency of the mechanical system (Shahnazar et al., 2016). Therefore, reducing wear and coefficient of friction can be considered as a great saving to make the process economical (Padmanabhan et al., 2016). Reducing the wear and friction is one of the major challenges in any sliding surfaces that move relative to each other ( $\mathrm{Li}$ et al., 2015). Basically, durability, reliability and efficiency of components depend on the friction and wear of sliding surfaces (Xie et al., 2016). Over decades, different types of lubricants were used to reduce the friction. However, friction and wear cannot be eliminated completely but can be minimized up to an extent by proper utilization of lubrication between the sliding or moving surfaces (Singh et al., 2017). In the industry, wearing of the tool material during machining processes is a major concern (Maruda et al., 2017). To reduce the coefficient of friction and wear various lubricants are used (Ezugwu et al., 2004). The waterbased emulsion emerged as a good coolant and lubricants because of their availability as well as better thermal conductivity and low viscosity (Xia et al., 2017). However, oil-based lubricants oxidize easily at high pressure and temperature condition which deteriorates the performance of moving parts (Amiril et al., 2017). In most of the engineering applications, lubrication was unable to perform effectively due to various reasons (Krolczyk et al., 2016). The effectiveness of lubricant also reduces under extreme pressure (EP) and high load condition (Tang and $\mathrm{Li}, 2014$ ). The waterbased emulsion cannot be oxidized easily at high temperature, pressure and load condition because 
of its high specific heat capacity and thermal conductivity. Moreover, water-based emulsions show good lubrication properties and can carry away the generated heat at rubbing surface more efficiently under extreme condition due to the ability of thin film formation at the contact zone (Liang et al., 2017). Due to continuous usage, the lubricants tend to lose their properties. Hence there is a need of their maintenance to sustain their properties for a longer duration. As the fluid degrades and becomes unsuitable for further use, therefore it is disposed. Furthermore, the usage of synthetic and semi-synthetic lubricants may also cause environmental problems because of their hazardous nature and non-biodegradability (Wu et al., 2017). This has led to research in the field of application of nano-lubrication between moving parts. Therefore, a suitable lubricant is required which has excellent tribological and thermo-physical properties. Addition of metallic and nonmetallic nano-sized particles in conventional fluid improved its thermos-physical and tribological properties (Sharma et al., 2016). The nanofluid belong to a new class of cutting fluids with enhanced thermo-physical properties and heat transfer performance. The viscosity and thermal conductivity of nanofluids increase with an increase in the concentration of nanoparticles (Singh et al., 2017). Over a decade, the number of researchers have been investigating the effect of nanofluids on friction and wear analysis and it has been noticed that dispersion of $\mathrm{ZnO}$ with paraffinic mineral oil reduces the friction and wear compare to base oil (Gara and Zou, 2013). The nanoparticles act as a third body like solid lubricants, separate the bodies in contact and thus prevent wear by reducing the friction (Rodrigues et al., 2017). The nanoparticles deposit on the sliding surfaces and form a boundary layer between the moving parts (Ji et al., 2011). The depositions of nanoparticles at the worn out surfaces reduces the shear stress, which further reduces the coefficient of friction (Taha-Tijerina et al., 2013). However, sometimes nanoparticles are oxidized to form a protective film known as tribo-film and prevent the wear of moving components (Rodrigues et al., 2015). Interestingly, the optimum concentration of nanoparticles in the conventional lubricant is effective and beyond the optimum concentration, it deteriorates the performance of the nanofluids (Singh et al., 2017). The surfactants are used to avoid the agglomeration of nanoparticles and to enhance the thermal stability of nanofluids (Das et al., 2017; Tiara et al., 2017). Furthermore, the thin lubricating film between moving surfaces contains nanoparticles that are broken in smaller particles and reorient themselves at high load and temperature condition and reduces the coefficient of friction (Shrivastava et al., 2017). In another study of (Cong Mao et al., 2014), the addition of $\mathrm{Al}_{2} \mathrm{O}_{3}$ nanoparticles in deionized water reduced 
the friction coefficient by $34.20 \%$ and worn out the weight of the workpiece by $43.40 \%$ as compared to pure deionized water. Moreover, water-based cerium dioxide nanofluids have shown a significant reduction in friction and wear due to nanoparticle deposition on worn out surfaces (Zhao et al., 2013). Load bearing capacity of friction pairs was found to be increased on addition of fullerene-like-WS 2 in oil (Rapoport et al., 2003). Many other nanoparticles like $\mathrm{SiO}_{2}(\mathrm{Sharma}$ et al., 2017), $\mathrm{TiO}_{2}$ (Sharma et al., 2016), $\mathrm{MoS}_{2}$ (Pendleton et al., 2010; Kalin et al., 2012), Alumina (He et al., 2017; Sharma et al., 2018), Copper (Cu) (Yu et al., 2007), Fe and Co (Padgurskas et al., 2013), ZnO (Hernandez Battez et al., 2006; Alves et al., 2013) and CuO (Wu et al., 2007) etc. have been mixed to enhance the lubricating characteristics of their base oil by reducing frictional forces and wear. The unusual morphology of MWCNT and graphene platelets than other nanoparticles attracts many researchers. MWCNT nanofluids are also found effective because of its morphology, high flexural strength, high tensile strength and high modulus of elasticity (Zhang et al., 2014). Moreover, the carbon-based nanoparticles have potential in reducing the friction and wear because of their superior thermo-physical properties. The carbon-based nanoparticles have better thermal conductivity and low density over other metallic nanoparticles. Berman et al., (2014) has reviewed the literature on application of $\mathrm{GnP}$ and found that $\mathrm{GnP}$ is a new emerging and potential selflubricant as well as an additive to the lubricating oils. The graphene nanoparticles have sheet-like structure that increases its surface area that reduces metal to metal contact and transmits heat more efficiently and reduces friction and wear (Zhang et al., 2017). Rasheed et al., (2016) noticed that addition of graphene nanoflakes improves the thermal conductivity and viscosity of nanofluids compare to lubricant fluid. Yang et al., (2017) concluded that graphene-based lubricants reduces the wear and coefficient of friction by $91 \%$ and $53 \%$ respectively, compared to conventional lubricant. Furthermore, (Huang et al., 2016) observed that addition of cylindrical shaped nanoparticles (MWCNT) in lubricant fluid improves thermal conductivity that leads to the reduction of grinding force and improves the surface roughness in grinding operation. Moreover, (Sharma et al., 2017) and (Hu et al., 2011) concluded that mixing of more than two nanoparticles (hybrid) in water-based emulsion, improves the lubricant's performance such as anti-friction, antiwear, extreme pressure and load carrying capacity of lubricants. MWCNT and graphene shows similar physical and chemical characteristics such as conjugate electronic structure and surface properties in spite of exhibiting different morphology (Yu et al., 2008; Maruda et al., 2015). The surfactant functionalized MWCNT has been found to improve lubricating properties of a lubricant 
such as load carrying capacity, anti-wear characteristics and friction reduction properties (Peng, Hu and Wang, 2007). Furthermore, many investigations have shown promising results regarding improvement of tribological properties of oils by adding GnP nanoparticles (Lin et al., 2011; Mehrali et al., 2014; Zhao et al., 2016) and MWCNT nanoparticles (Chen et al., 2005; Wang et al., 2010; Ettefaghi et al., 2013). Therefore, study of tribological behavior of MWCNT and GnP is important to explore the impact of carbon-based nanoparticles on friction and their wear behavior. Furthermore, (Katiyar et al., 2016) noticed that addition of MWCNT has shown excellent wear resistance and with graphite is superior in tribological performance.

In the present study, friction and wear behavior of MWCNT and GnP in water-based emulsion (nano-lubricants) are investigated at different nanoparticle concentration and rotating speeds on pin-on-disc tribometer. Different nanofluid samples are prepared by mixing of MWCNT and GnP in a water-based emulsion. A comparative analysis is carried out under different lubrication conditions (dry, pure emulsion and various concentrations of MWCNT and GnP nanofluids) at different sliding speeds. The field emission scanning electron microscopy (FESEM) analysis is conducted to investigate the influence of nanolubricants on wear and coefficient of friction.

Furthermore, the mechanisms behind the reduction of friction and wear under the different lubricating condition are also explained.

\section{Materials and Methods}

This study mainly focusses on tribological performance of different nanofluid samples on pin-ondisc tribometer. To conduct the tests different samples of MWCNT and GnP nanoparticles were selected. All the tests were performed on the pin on disc tribometer under different lubricating conditions.

\subsection{Sample preparation and characterization of nanofluids}

All the nanofluid samples are prepared by mixing two different carbon-based nanoparticles in conventional lubricant. In this study, two different morphology of nanoparticles such as multiwalled carbon nanotubes (cylindrical shape, 2-15 walls, 5-25 nm outer dia.; 2-8 nm inner dia. and 2-10 $\mu \mathrm{m}$ in length) and graphene nanoplatelets with average thickness: 10-20 nm and average particle size: $5 \mu \mathrm{m}$ are used. The solid carbon-based nano-materials and surfactant were procured from Alfa Aesar®. To prepare the emulsion the industrial metalworking fluid Servo cut-S oil is 
selected because of its extensive application in various machining processes. This oil forms milky solution upon mixing with water which forms base lubricant for the present investigation. The conventional lubricant was a water-based emulsion which consists of 5\% vol. the concentration of servo cut-S oil and $95 \%$ deionised water.

Figure1 FESEM images of (a) graphene nanoplatelets (b) multi-walled carbon nanotubes

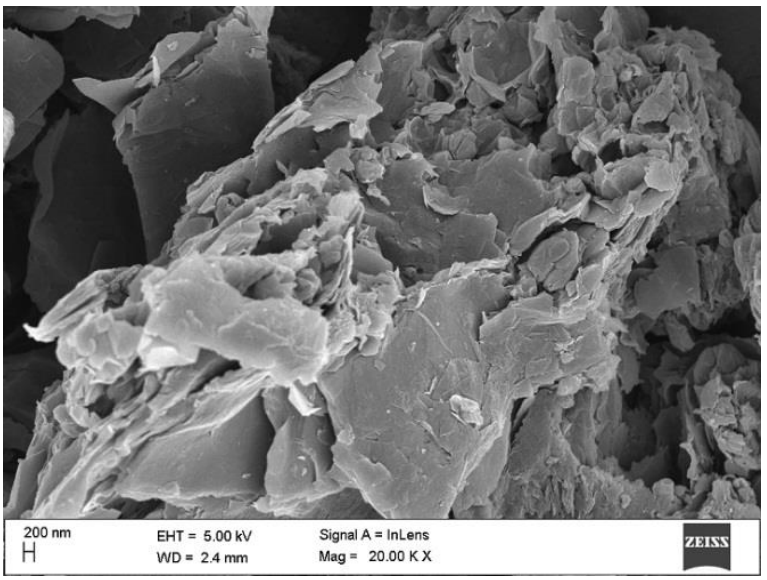

(a)

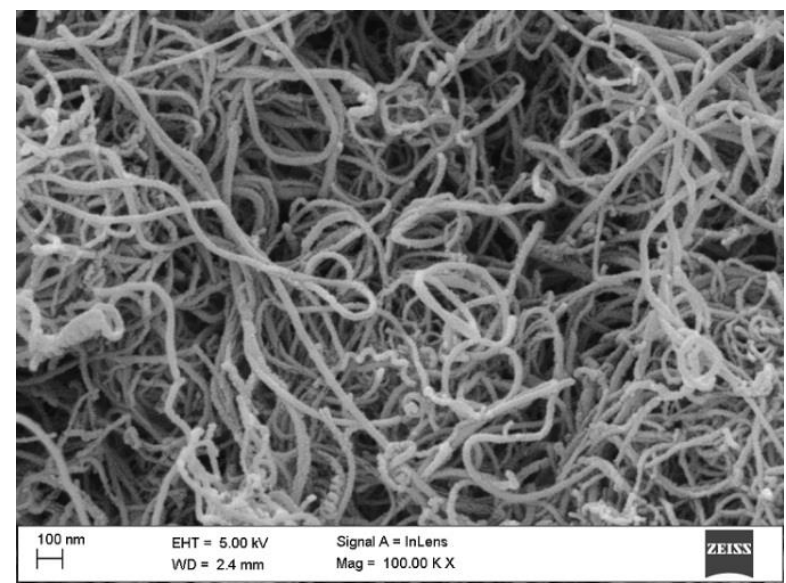

(b)

Fig. 1 shows the field emission scanning electron microscopy (FESEM) of multiwalled carbon nanotubes and graphene nanoplatelets. The nanofluid samples in various concentrations were prepared by the dispersion of MWCNT and GnP in a water-based emulsion. The surfactant CTAB (cetyltrimethylammonium bromide) was added to the conventional fluid to avoid the agglomeration. The ultrasonic vibrator (make-Toshiba, India) generating ultrasonic pulses at $36 \pm 3$ $\mathrm{KHz}$ at $100 \mathrm{~W}$ power was used for sonication of nanofluid samples. All the nanofluid samples were ultrasonicated for 4-6 hours to get the uniform dispersion of nanoparticles in conventional lubricant.

The different concentrations $0.05,0.2,0.4,0.6,0.8$ and $1.0 \mathrm{wt} . \%$ of nanofluids were prepared with the addition of MWCNT and graphene nanoplatelets in a water-based emulsion. Every time fresh samples were prepared to measure the thermo-physical properties. For each concentration, thermal conductivity and viscosity of the nanofluid samples were measured at four different temperatures. The effect of temperature and nanoparticles concentration on thermal conductivity and viscosity were analysed. The transient hot-wire instrument (KD2 Thermal Properties Analyzer, Decagon Devices, Inc., USA) was used to measure the thermal conductivity of nanofluid samples. The instrument has a variable heat source that can record the thermal conductivity and thermal 
resistivity at different temperatures. Furthermore, digital viscometer apparatus was used to measure the viscosity of nanofluid samples. The setup contains variable temperature control unit to adjust the temperature of bath and probe. The measuring probe of viscometer was submerged in nanofluid samples to measure the viscosity at different temperatures.

Figure 2 Thermal conductivity (W/m-K) versus wt. \% concentration of (a) GnP (b) MWCNT at different temperatures, and variation of viscosity (cP) with different wt. \% concentration of (c) GnP (d) MWCNT at different temperatures.

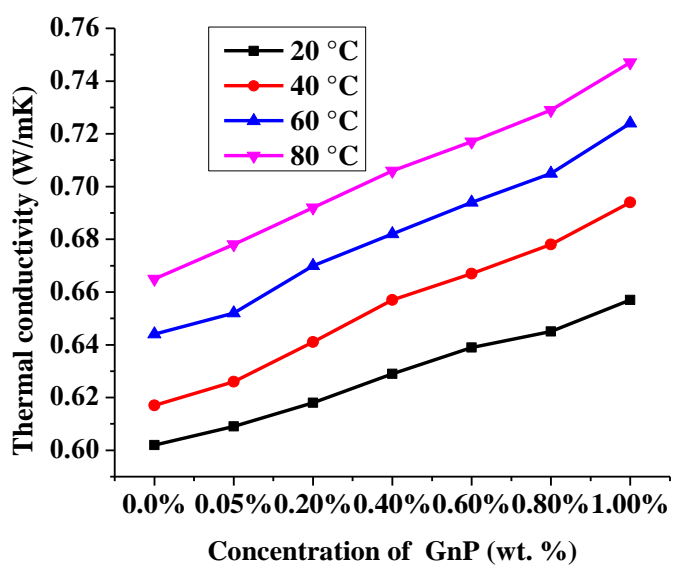

(a)

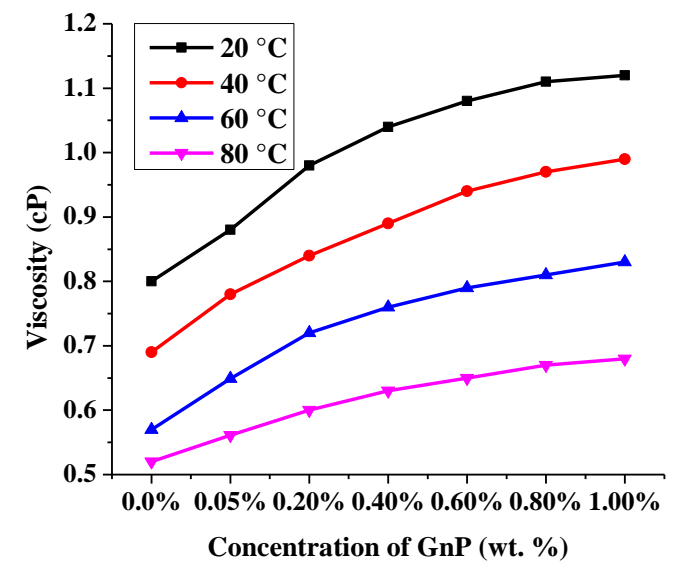

(c)

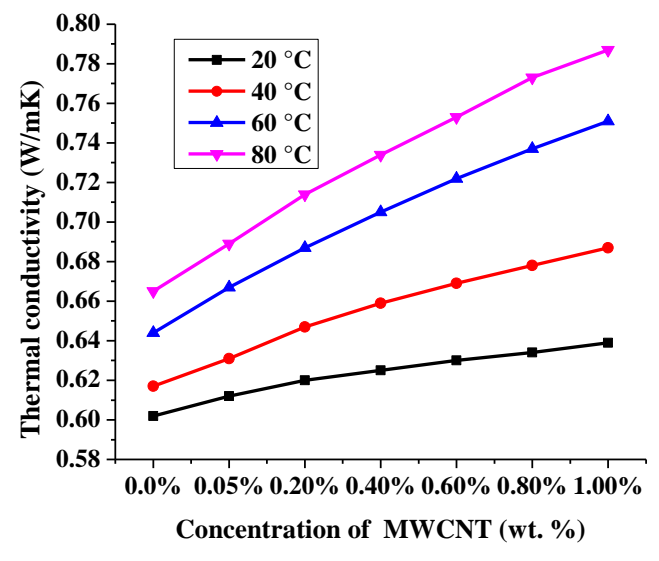

(b)

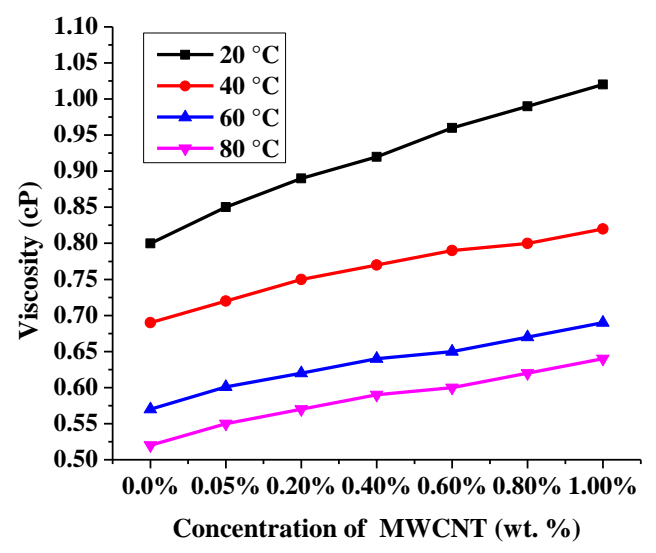

(d)

The carbon-based nanoparticles mixed nanofluids shows a significant improvement in the thermal conductivity compare to water-based emulsion (conventional lubricant). Fig.2 (a, b) shows 
the enhancement in the thermal conductivity of GnP and MWCNT mixed nanofluids with the increase of nanoparticle concentration compare to the conventional lubricant. Furthermore, thermal conductivity increases with increase in the temperature of nanofluid samples. The increase in the temperature accelerates the Brownian motion of nanoparticles, that results in an increase of thermal conductivity with temperature. The addition of graphene nanoplatelets in conventional lubricant observed an improvement of $1.95 \%$ to $12.33 \%$ in thermal conductivity for varying concentration (from 0.05 to $1.00 \mathrm{wt} . \%$ ) as compared to conventional lubricant at $80{ }^{\circ} \mathrm{C}$. However, the addition of multi-walled carbon nanotubes observed an improvement of $3.6 \%$ to $18.34 \%$ in thermal conductivity for varying concentration (from 0.05 to $1.00 \mathrm{wt} . \%$ ) as compared to conventional lubricant at $80^{\circ} \mathrm{C}$. Therefore, the thermal conductivity of GnP and MWCNT mixed nanofluids depends on the concentration of nanoparticles as well as temperature.

To measure the viscosity of various nanofluids samples LVDV-II+Pro Brookfield digital viscometer (cone and plate) with a computer-controlled was used. The setup consists of variable temperature control bath to set the nanofluid temperature at different values. A similar trend was observed during the measurement of viscosity of GnP and MWCNT mixed nanofluids samples with the variation of temperatures. All the nanofluid samples showed improvement in the viscosity with an increase in nanoparticle concentration. Fig.2 (c, d) shows that the addition of graphene nanoplatelets in conventional lubricant observed an increment of $7.88 \%$ to $30.77 \%$ in viscosity for varying concentration (from 0.05 to $1.00 \mathrm{wt}$.\%) as compared to conventional lubricant at 80 ${ }^{\circ} \mathrm{C}$. Similarly, the addition of multi-walled carbon nanotubes observed an improvement of $5.77 \%$ to $23.07 \%$ in viscosity for varying concentration (from 0.05 to $1.00 \mathrm{wt} . \%$ ) as compared to conventional lubricant emulsion at $80{ }^{\circ} \mathrm{C}$. However, it has been noticed that increase in the temperature reduces the viscosity of all nanofluid samples.

The measurement result confirms that thermal conductivity and viscosity of all the nanofluid samples have increased with increase in the concentration of nanoparticles and shows temperature and concentration-dependent behaviour. The increase in the thermal conductivity of nanofluid samples imparts the cooling between the pin and disc while higher viscosity hinders the spray of nanolubricant with minimum quantity lubrication (MQL) technique. To balance the positive effect of thermal conductivity and loss of pumping power due to higher values of viscosity an optimum concentration of nanoparticles has been used in the conventional lubricant. All the nanofluid 
samples are kept on the ultrasonic vibrator for at least 2-3 hours to get the stable and uniform dispersion of nanoparticles.

\subsection{Materials and Tribological tests}

Two materials in direct contact always have some coefficient of friction value. However, this value can be minimised using proper lubrication. Therefore, to measure the frictional force and wear of material several experiments were performed under different lubrication conditions. The rotatory pin-on-disc tribometer (Ducom Instrument Pvt. Ltd., India) was used to measure the wear rate as well as the coefficient of friction. The tribometer has maximum 2000 RPM and $1000 \mathrm{~N}$ load capacity. The AISI 304 stainless steel was selected as pin and disc material to test the tribological performance of two different nanofluids at ambient temperature $25 \pm 1{ }^{\circ} \mathrm{C}$. The cylindrical pin having $3 \mathrm{~mm}$ diameter and $50 \mathrm{~mm}$ length and disc with $155 \mathrm{~mm}$ pitch circle diameter and $8 \mathrm{~mm}$ thickness were selected for experimentation. The hardness and surface roughness value of disc surface was $130 \pm 5 \mathrm{HV}$ and $0.258 \mu \mathrm{m}$, respectively. Table 1 illustrates the experimental details about the test on tribometer.

Table 1 Details of the material, different nanofluids and test on pin-on-disc tribometer.

\begin{tabular}{ll}
\hline Name & Description \\
\hline Pin-on-disc tribometer & Make -DUCOM \\
& Load range $-10-200 \mathrm{~N}$ \\
& Rotational speed $-200-2000 \mathrm{rpm}$ \\
& Frictional force measurement $-0-200 \mathrm{~N}$ \\
& Material - AISI304 Stainless steel \\
\hline Disc and pin specimen & $3 \mathrm{~mm}$ diameter of Pin and $150 \mathrm{~mm}$ pitch diameter of the disc \\
\hline Servo cut S & Flashpoint - $150^{\circ} \mathrm{C}$ minimum \\
& Kinematic viscosity $-20 \mathrm{cSt} @ 40^{\circ} \mathrm{C}$ \\
\hline Conventional lubricant & Water-based emulsion $(95 \%$ water $+5 \%$ Servo cut S Oil) \\
\hline Nanofluids & MWCNT and GnP nanoparticles mixed nanofluids \\
\hline Test environment & Dry, conventional lubricant, $0.2,0.4,0.6,0.8$ and 1.0 wt.\% \\
\hline Sliding distance & concentration of MWCNT and GnP \\
\hline Sliding speed variation & $450 \mathrm{~m}$ \\
\hline Load & $20,40,60,80,100$ and $120 \mathrm{~m} / \mathrm{min}$ \\
\hline Nanofluid flow rate & $40 \mathrm{~N}$ \\
\hline
\end{tabular}


Figure 3 (a) Pin-on-disc experimental setup (b) Sliding tracks on rotating disc (c) Pin and disc machine (d) closed view of sliding pin on rotating disc (Singh et al., 2017).

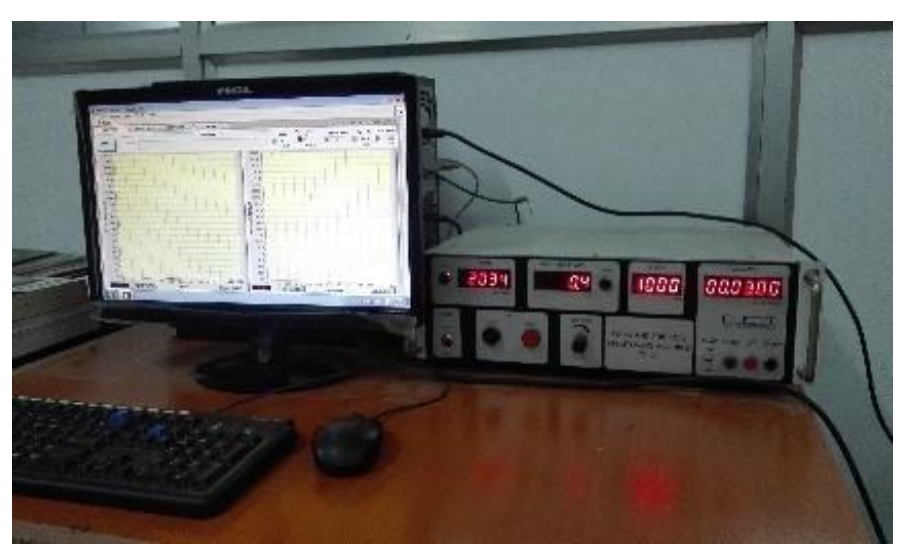

(a)

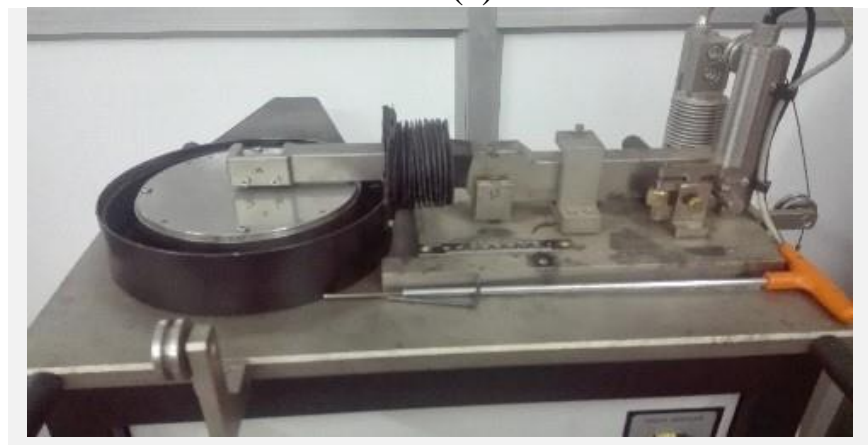

(c)

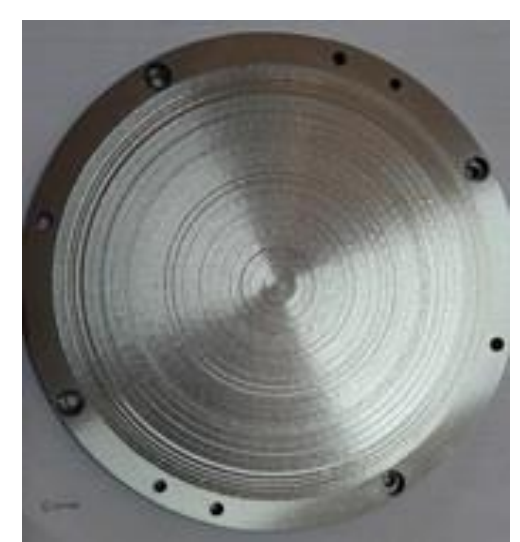

(b)

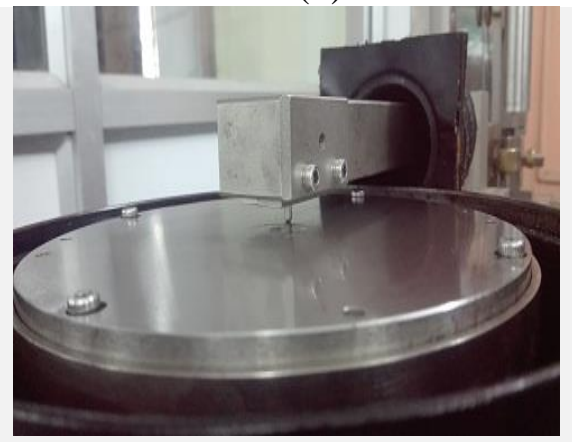

(d)

Fig. 3 shows the complete experimental setup used during the pin-on-disc test. The load $(40 \mathrm{~N})$ and sliding distance $(450 \mathrm{~m})$ was kept constant throughout the experiments. The pin specimen is pressed against the disc at a specified load usually by means of an arm or lever with attached weights. To minimise the error sliding track of the disc has been changed for each run. To ensure the smooth operation, disc and pin were fixed properly in the holder, and the new pin was used for each run. The instrument has variable RPM selector. The RPM may be changed in order to maintain the constant sliding speed after each run. The disc was properly cleaned with acetone to remove the debris and oil mark from the surface. The tests were performed at various sliding speeds $(20,40,60,80,100$ and $120 \mathrm{~m} / \mathrm{min})$ under different lubricating conditions (dry, pure conventional lubricant, 0.2, 0.4, 0.6, 0.8 and $1.0 \mathrm{wt} . \%$ concentrations of GnP and MWCNT mixed nanofluids). All the nano-lubricants were supplied in the mist form at a flow rate of 20 $\mathrm{ml} / \mathrm{min}$ at a pressure of 4 bar with orientation angle of $45^{\circ}$ and $50 \mathrm{~mm}$ standoff distance. The values 
of frictional force and wear with time were recorded at different sliding speeds under different lubricating conditions at constant load throughout the experiments.

\section{Results and Discussion}

The experimental results regarding wear and frictional forces were recorded and analysed for different lubrication conditions. The variation of wear and coefficient of friction with sliding speed under different nanofluids has been investigated. The FESEM images were used to analyse the wear out the surface of the pin, and the metallurgical microscope was used to analyze the disc tracks for the different lubricating condition. Additionally, the comparative tribological analysis was carried out for GnP and MWCNT mixed nanolubricants.

\subsection{Analysis of wear depth using MWCNT and GnP mixed nanofluids}

The experimental values of wear were investigated with respect to sliding speed as well as the concentration of both nanoparticles. Fig. 4 shows the variation of wear depth with respect to sliding speed at different lubricating conditions. From results, it has been noticed that addition of $\mathrm{GnP}$ and MWCNT in conventional lubricant significantly reduces the wear as compared to the dry and conventional lubricant. For both the nanofluids, wear of material reduces with increase in the concentration and becomes almost constant after 0.8 wt.\% concentration. Fig. 4 (a, b) shows that use of 0.8 wt. $\% \mathrm{GnP}$ based nanolubricant reduces the wear by $61.80 \%, 59.05 \%, 54.59 \%, 48.14 \%$, $42.60 \%$ and $39.54 \%$ compare to conventional lubricant at $20 \mathrm{~m} / \mathrm{min}, 40 \mathrm{~m} / \mathrm{min}, 60 \mathrm{~m} / \mathrm{min}, 80 \mathrm{~m} / \mathrm{min}$, $100 \mathrm{~m} / \mathrm{min}$ and $120 \mathrm{~m} / \mathrm{min}$ sliding speeds, respectively. Similarly, at $0.8 \mathrm{wt} \%$ MWCNT mixed nanolubricant reduces the wear by $47.35 \%, 747.18 \%, 44.92 \%, 41.33 \%, 37.93 \%$ and $35.74 \%$ as compared to conventional lubricant at $20 \mathrm{~m} / \mathrm{min}, 40 \mathrm{~m} / \mathrm{min}, 60 \mathrm{~m} / \mathrm{min}, 80 \mathrm{~m} / \mathrm{min}, 100 \mathrm{~m} / \mathrm{min}$ and $120 \mathrm{~m} / \mathrm{min}$ sliding speeds, respectively.

The wear of pin material increases with increase in the sliding speed. This may be due to the generation of more wear debris at high speeds, which starts the breaking of nano thin-layer of nanoparticles between the surface and leads to abrasive wear. Furthermore, at lower sliding speeds the nanoparticles are acting like a roller bearing and creating the rolling effect between the sliding surfaces. However, at higher sliding speeds with an increase of nanoparticle concentration the proper flushing of wear debris could not take place and thus increases the wear rate (Sharma et al., 2015). 
Figure 4. Variation of wear of pin material with varying sliding speeds at a concentration of (a) GnP and (b) MWCNT mixed nanofluid.

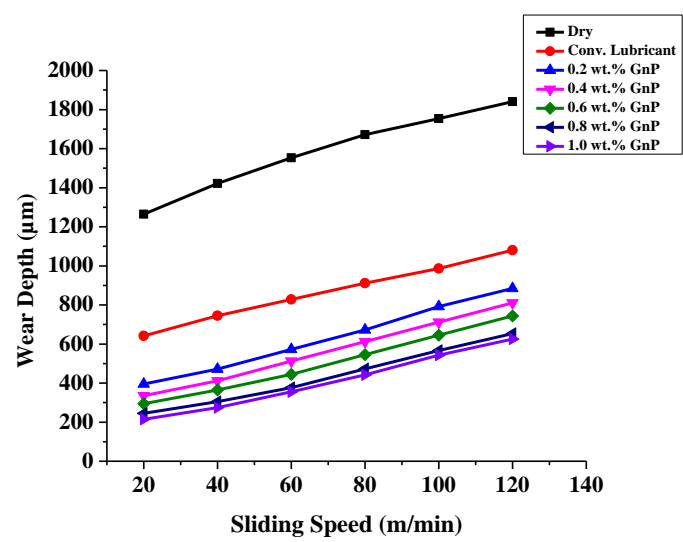

(a)

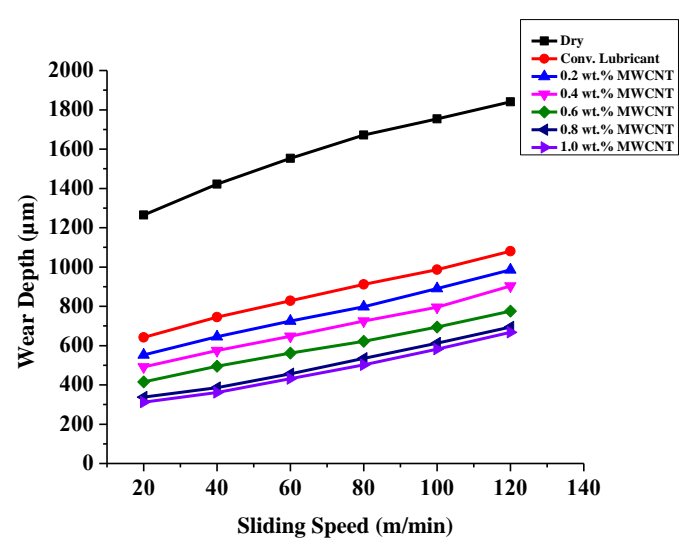

(b)

Moreover, Fig 6 (i) and fig (1) also show that smoother surfaces were observed with the increase of $\mathrm{GnP}$ and MWCNT nanoparticles concentration in conventional lubricant. The graphene-based nanofluids were found more effective in reducing the wear compare to multiwalled carbon nanotubes mixed nanofluids. The GnP has a two-dimensional structure with multiple plates and has weak Vander wall forces between these nanolayers (Dai et al., 2016). The sheet-like structures act as a third body solid lubricant, which has high strength and shear capabilities making the rubbing surfaces smoother. Furthermore, these nano-sheets structure of graphene allows it easily to slide at the sliding zone, which forms a nano-sized thin layer between two mating surfaces. Due to the ploughing action, a number of nanoparticles might have filled into the asperities of the surfaces, which reduces the depth of wear. Similarly, the addition of MWCNT in conventional lubricant reduces the wear with an increase of concentration. The MWCNT particles are cylindrical in shape (Fig. 1(b)) and have high flexural and tensile strength that reduces the shear stress. During the test, the multiple cylindrical tubes of MWCNT have been acting as a bearing between the pin and disc. These carbon nanotubes were filled inside the asperities of the pin and disc surfaces, which further reduced the wear depth.

\subsection{Analysis of coefficient of friction using MWCNT and GnP mixed nanofluids}

The frictional force values were recorded during the tribological tests on tribometer. The constant load $40 \mathrm{~N}$ was applied during all the experiments. Furthermore, the coefficient of friction was 
determined all the frictional forces under different lubricating conditions. Fig. 5 shows the variation of coefficient of friction with respect to sliding speed under different lubricating conditions. The experimental results show that the addition of GnP and MWCNT in conventional lubricant significantly reduces the coefficient of friction compare to dry and conventional lubricant. Furthermore, both the nanofluid samples have shown significant amount reduction in the coefficient of friction with the increase in the nanoparticle concentration, and after $0.8 \mathrm{wt} . \%$ friction coefficient has become almost constant.

Figure 5. Variation of the coefficient of friction with varying sliding speeds at a concentration of (a) GnP and (b) MWCNT mixed nanofluid.

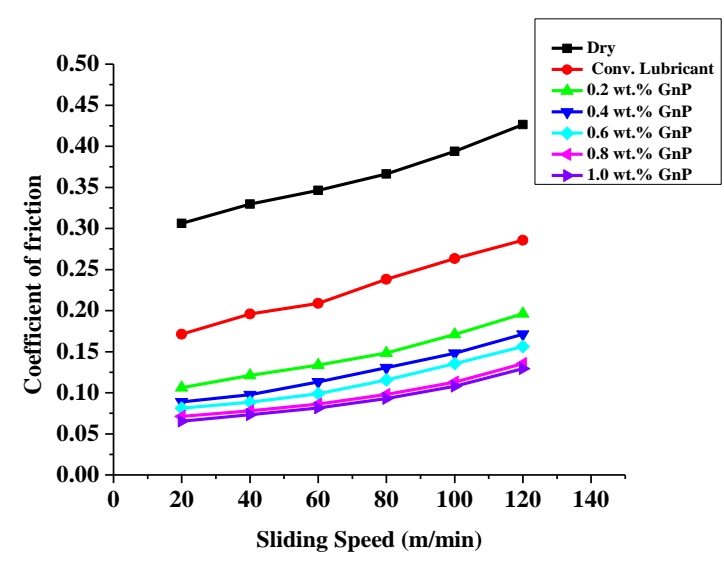

(a)

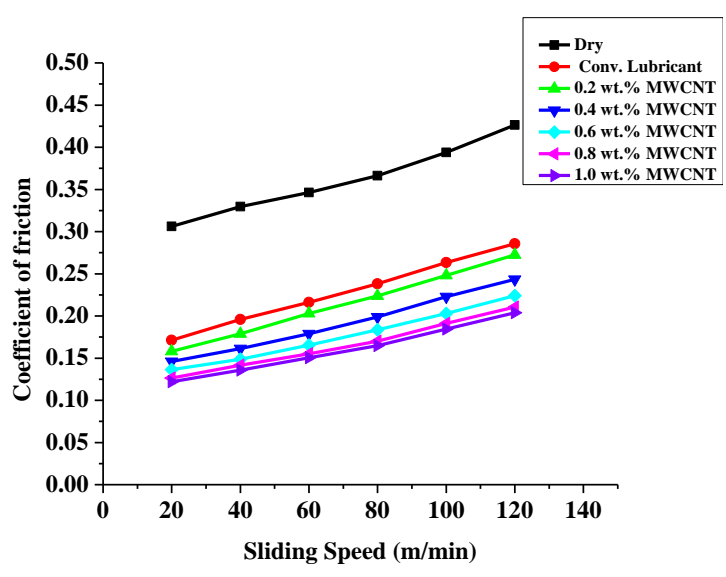

(b)

Fig. 5 (a-b) shows a reduction in the coefficient of friction from $58.4 \%$ to $52.54 \%$ as compared to conventional lubricant with a variation of sliding speeds of the disc (from 20-120 $\mathrm{m} / \mathrm{min}$ ) at 0.8 wt.\% GnP mixed nanolubricant. Similarly, use of 0.8 wt.\% MWCNT mixed nanolubricant has reduced the coefficient of friction from $28.64 \%$ to $26.26 \%$ as compared to conventional lubricant with a variation of sliding speeds of the disc (from $20-120 \mathrm{~m} / \mathrm{min}$ ). The GnPs possess sheet-like structure while MWCNT has cylindrical shapes. The thin graphene sheet has weak Vander wall forces, which slides easily between the rubbing/sliding surfaces and reduces the coefficient of friction. This sheet-like graphene-based nanolubricant forms a thin film at the interfacial space that reduces the coefficient of friction between pin and disc surfaces. The GnP nanoparticles also entrapped in the sliding surface of pin and disc (Fig. 6). The worn-out surface of pin materials provides the clear evidence of forming a thin film that might have reduced the 
coefficient of friction. The metallurgical microscope images of disc tracks at a dry, wet and different concentration of nanolubricants provide an evidence of reduced wear debris that leads to decrease in friction coefficient. Moreover, the FESEM images of pin surface under different MWCNT nanolubricant samples were investigated. The micrographs showed clear entrapment of MWCNT nanoparticles on the pin surface and formed a protective film that reduced the coefficient of friction. The cylindrical shape of MWCNT may act like roller bearing during sliding action, which further reduced the coefficient of friction.

\subsection{Analysis of worn-out surfaces under different lubricating conditions}

The sliding surfaces of pins were studied using FESEM during pin-on-disc test Fig. 6 shows the FESEM micrographs under different lubrication conditions. The images were recorded under different magnifications starting from $100 \mathrm{X}$ to $50.00 \mathrm{KX}$ to get the qualitative difference in the sliding surface morphology. From FESEM images, it is noticed that smoother surfaces were observed under GnP and MWCNT nano-lubricants compare to dry and pure conventional lubricant.

Figure 6. FESEM images of pin surface under (a-c) Dry, (d-f) Pure conventional lubricant and (g-i) 0.8 wt.\% MWCNT nanofluid and (k-m) 0.8 wt.\% GnP nanofluid test condition (pin dia. = $3 \mathrm{~mm}$, sliding speed $=60 \mathrm{~m} / \mathrm{min}$, load $=40 \mathrm{~N})$.

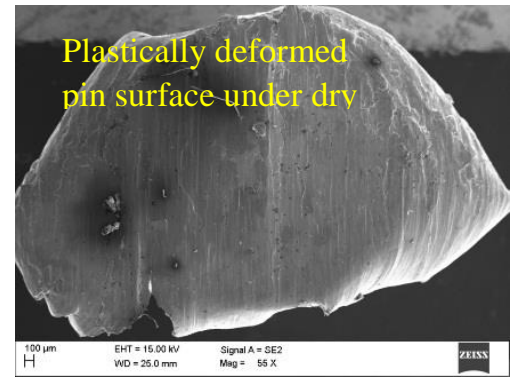

(a)

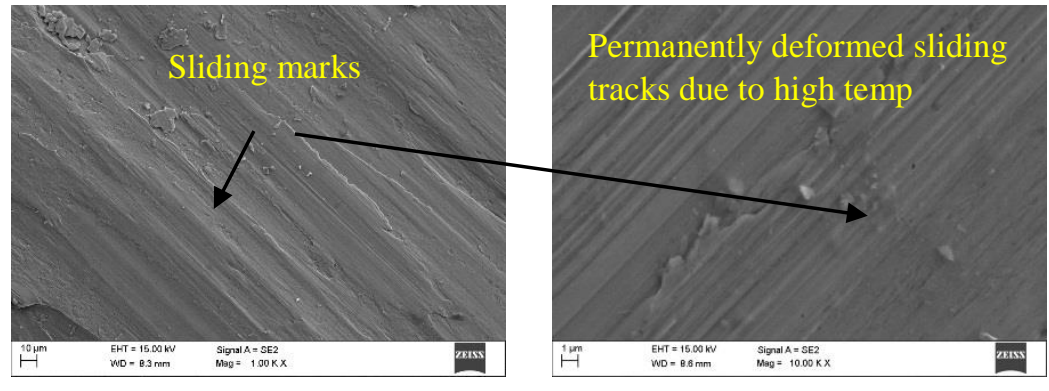

(b)

(c)

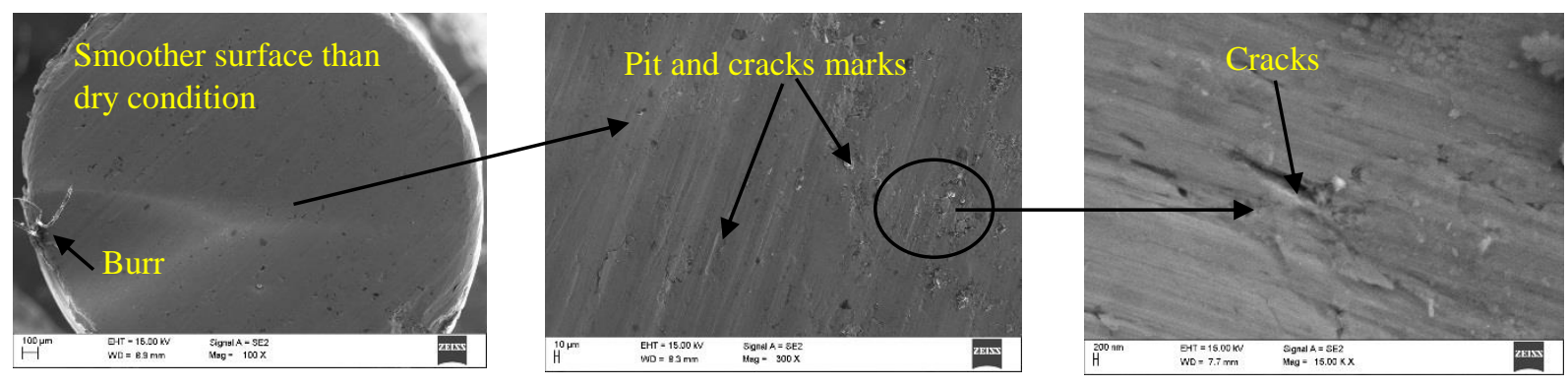


(d)

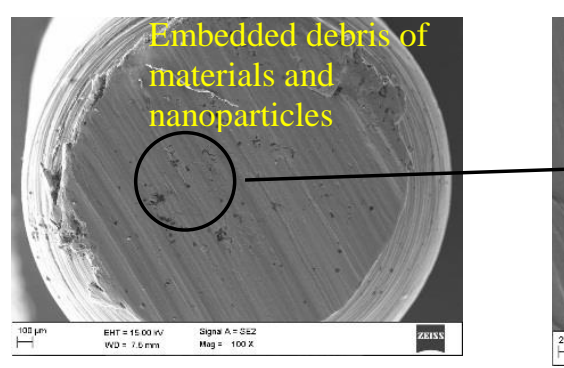

$(\mathrm{g})$

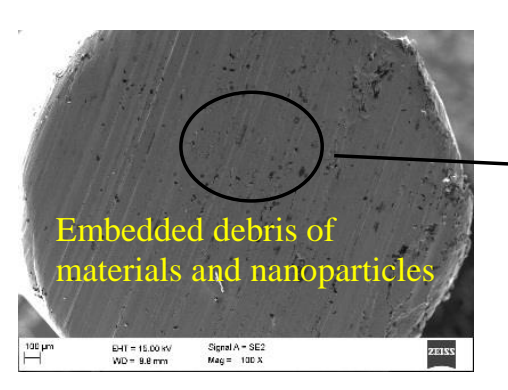

(j) (e)

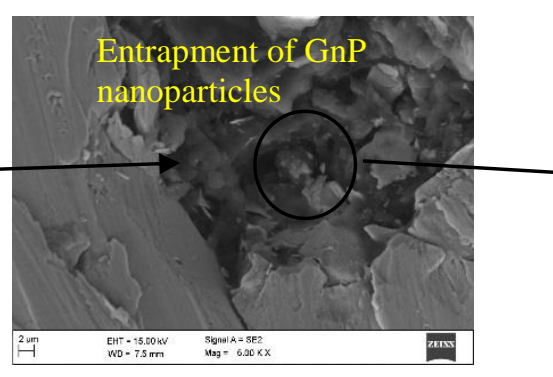

(h) (f)

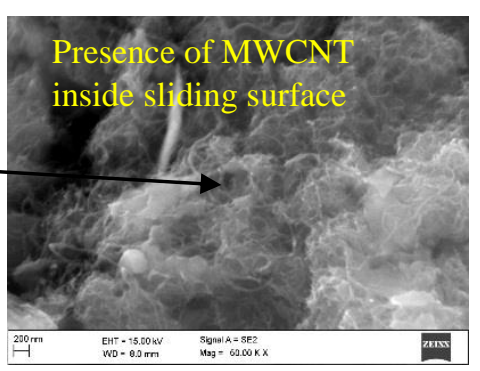

(i)

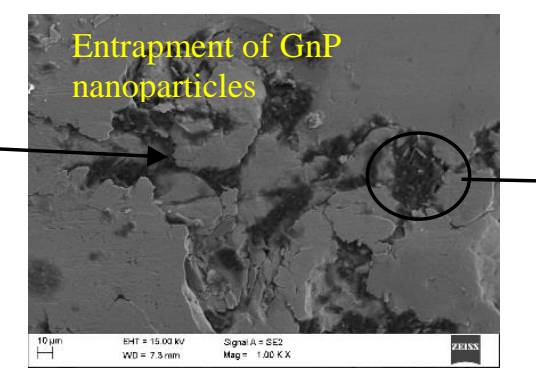

(k)

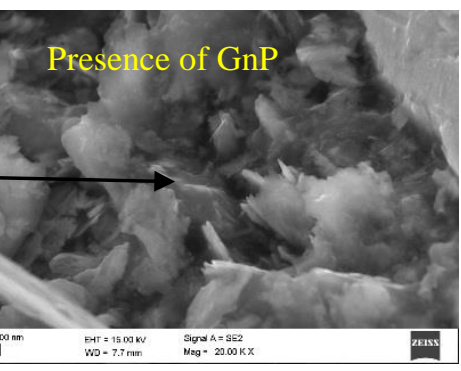

(1)

The FESEM images analysis reveals that addition of GnP mixed nanolubricant performed better and best quality of the surface is observed as compared to MWCNT mixed nanolubricant. The higher magnification $(20.00 \mathrm{KX}$ to $50.00 \mathrm{KX})$ of sliding surfaces show the clear evidence of entrapment of $\mathrm{GnP}$ and MWCNT into the pin surfaces. The entrapment of GnP and MWCNT nanoparticles forms a thin protective film that reduces the wear and coefficient of friction between the sliding surfaces.

Figure 7. Metallurgical microscopic images of disc tracks at different test conditions (Dry, conventional lubricant, MWCNT and GnP nanofluid at (pin dia. $=3 \mathrm{~mm}$, sliding speed $=60 \mathrm{~m} / \mathrm{min}$, load $=40 \mathrm{~N})$.

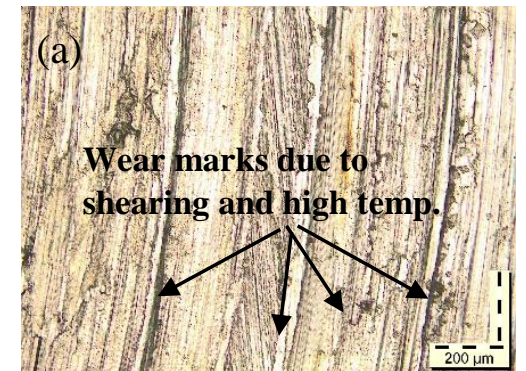

Dry

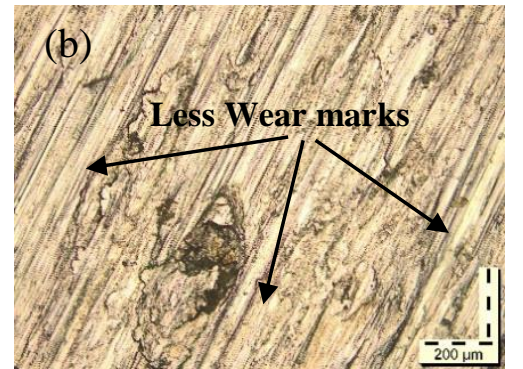

Conventional lubricant

(e)

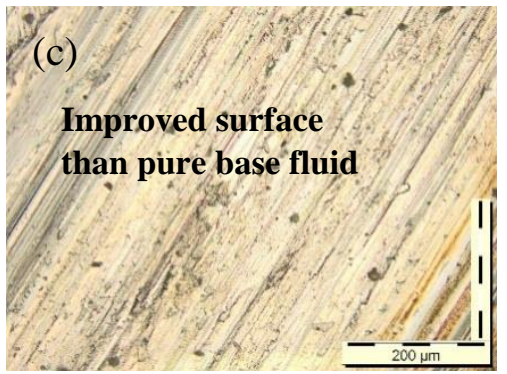

0.2 wt. $\% \mathrm{GnP}$ 


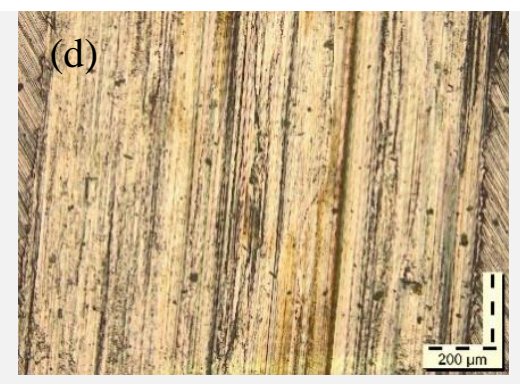

0.4 wt. $\% \mathrm{GnP}$

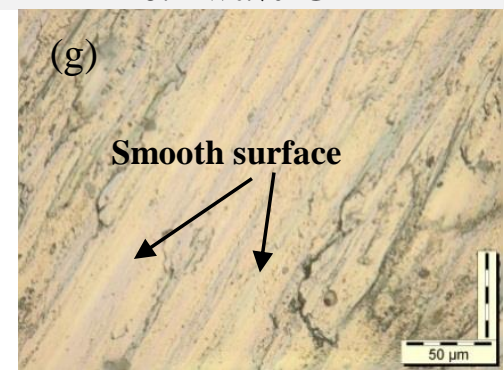

1.0 wt. $\% \mathrm{GnP}$

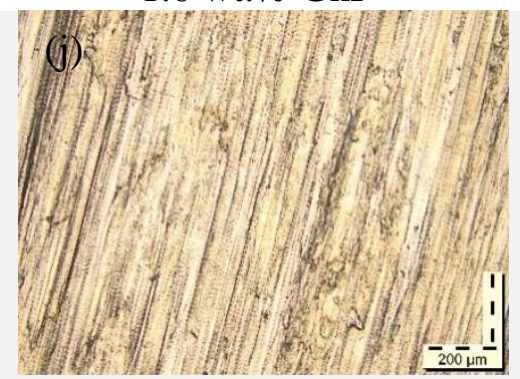

0.6 wt.\% MWCNT

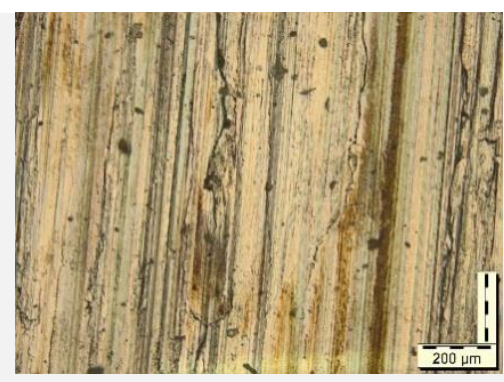

0.6 wt.\% GnP

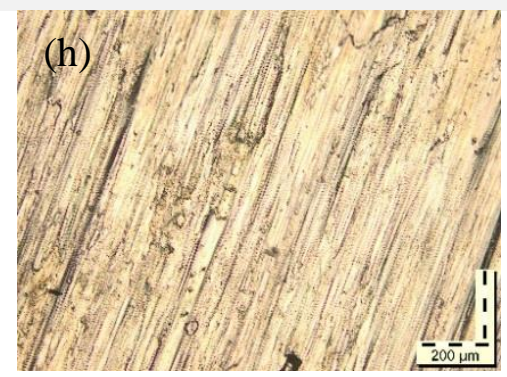

0.2 wt. \% MWCNT

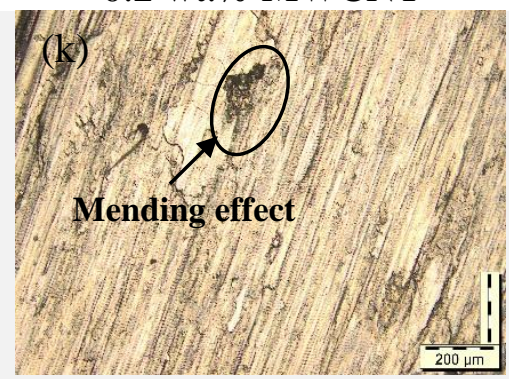

0.8 wt.\% MWCNT

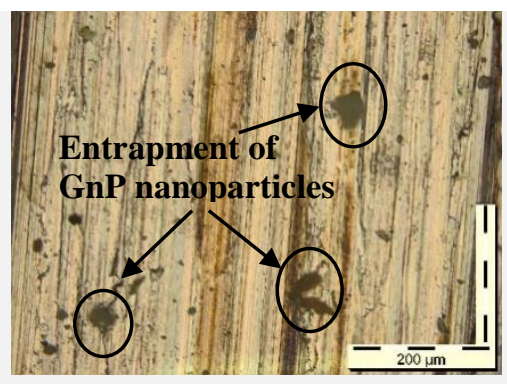

0.8 wt. $\% \mathrm{GnP}$

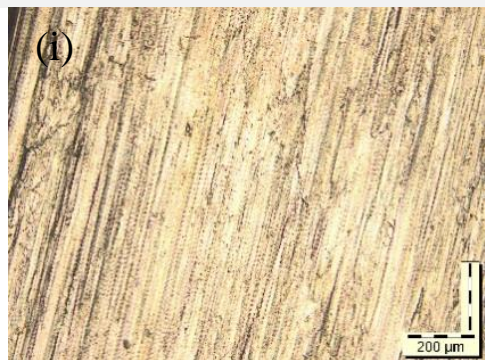

0.4 wt.\% MWCNT

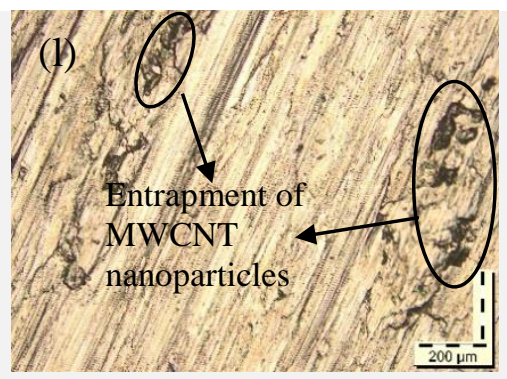

1.0 wt. \% MWCNT

The application of graphene-based nanolubricant samples has shown better results compare to MWCNT based nanofluids. Moreover, both nanolubricants behaved differently due to the difference in the morphology of GnP and MWCNT nanoparticles. Fig. 7 shows the metallurgical microscopic images of disc track surfaces under dry, conventional lubricant and different concentrations of GnP and MWCNT nanolubricant. More number of nanoparticles break at higher sliding speeds and makes the fluid film thicker and blocks the rubbing surfaces that leads to the adhesive wear. The thin graphene sheet slides easily between the rubbing/sliding surfaces and MWCNTs act like roller bearing. The metallurgical microscope images of sliding tracks confirm the clear entrapment of GnP and MWCNT on the disc track surface. The metallurgical microscope images of disc tracks show that at higher speed more wear particles were developed that adhered to the surfaces which eventually increased the coefficient of friction.

\subsection{Synergistic effect of GnP and MWCNT mixed nano-lubricants}


The tribological test shows that application of GnP and MWCNT conventional lubricant reduced the wear and coefficient of friction. The structure or morphology of nanoparticles plays a vital role in the tribological performance of nanolubricants. The GnPs have higher surface area than MWCNT while MWCNTs have higher aspect ratio than GnP. This higher aspect ratio of MWCNT increases the thermal conductivity, which enhances the heat carrying capacity of nanolubricant. The exfoliated nano-sized graphene sheets have weak Vander wall forces that easily slides during sliding and forms a nano-sized layer. The FESEM images confirm the presence of thin layer and entrapment of nanoparticles into pin and disc surfaces.

Figure 8 Effect of different lubrication condition (a) Dry (b) conventional lubricant (c) GnP mixed lubricant (d) MWCNT mixed lubricant and (e) graphical representation of pin and disc surfaces

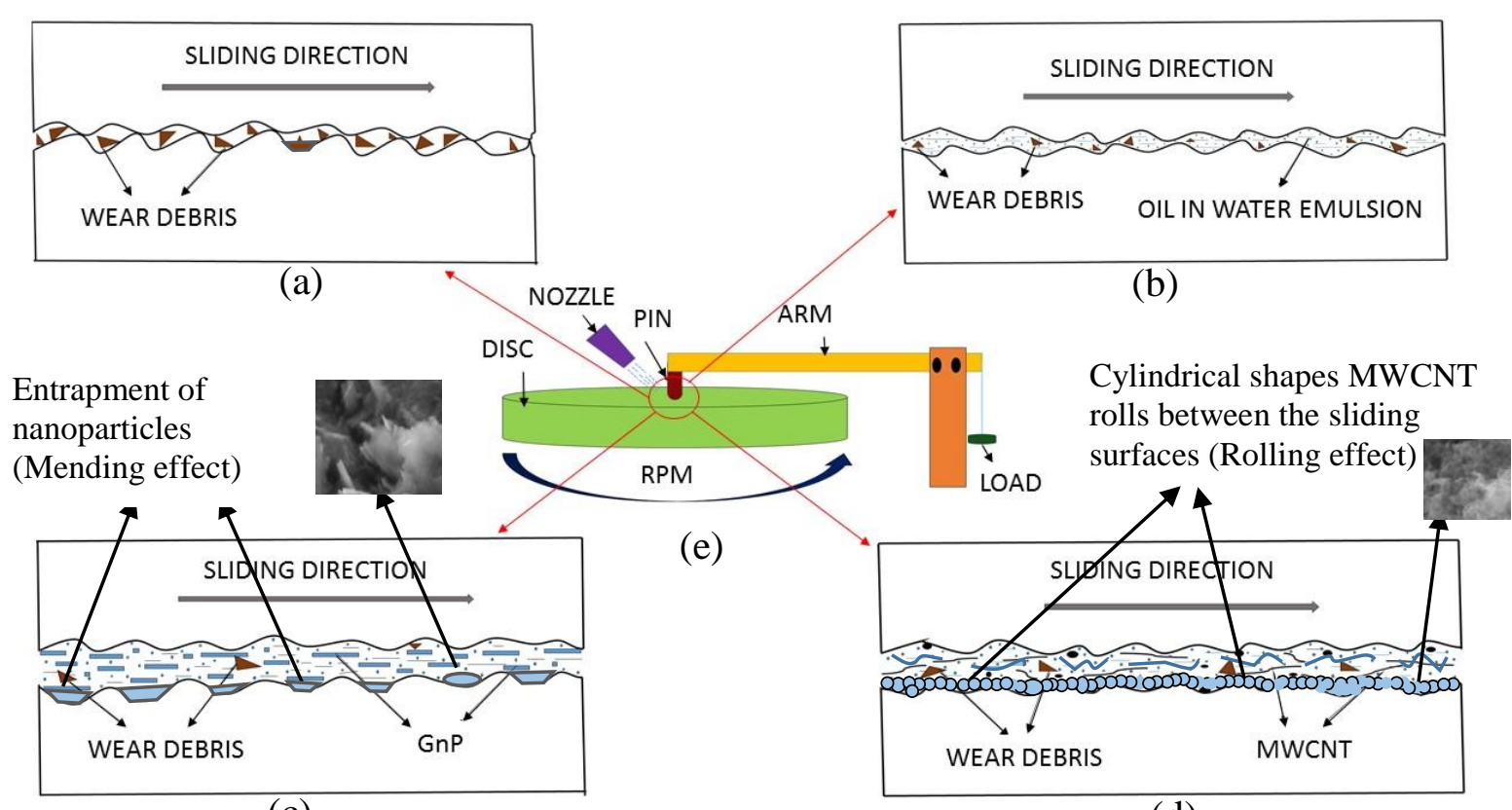

(c)

(d)

The schematic diagram (Fig. 8) shows the mechanism that takes place under different lubricating conditions. Moreover, it gives an insight view of reduction in the wear and coefficient of friction under various lubricating mechanisms. The shearing of thin graphene sheets results in the buckling, rippling, exfoliation, puckering and some case rupturing due to weak Vander wall forces. This graphene-based nanolubricant forms a thin film at the interfacial space that reduces the coefficient of friction between pin and disc surfaces. Fig. 8(e) illustrates the contact of the pin on rotating disc and a nozzle was attached to supply the nanolubricant at the sliding zone. 
Fig. 8(a) shows dry condition, there more wear debris are generated that leads to severe abrasive and adhesive wear. The FESEM image of the pin during dry condition supports the evidence of more worn-out zone and severe wear tracks that lead to the high coefficient of friction. Using a conventional lubricant (oil-in-water emulsion) on pin-on-disc, a reduction in coefficient of friction and wear is observed due to a thin liquid film formation that separates the asperities of sliding surface (Fig. 8b). The FESEM image of pin also shows the less worn out zone and wear track as compared to a dry condition. Fig. 8(c, d) shows that the addition of small concentration of GnP and MWCNT in conventional lubricant, a significant change in coefficient of friction and wear is observed because of nanoparticles thin film formation at the rubbing zone that separates the asperities of sliding surface effectively. Furthermore, nanoparticles are also deposited on the sliding surfaces and lower the loss of material is called mending effect. The GnP has platelets like structures which enables sliding mechanism and forms a thin film between sliding surfaces while in MWCNT multiple mechanisms are observed such as sliding, rolling and spinning due to its tubular structures (Zhao et al., 2016; Zhang et al., 2014). These different mechanisms become prevalent at different speeds such as at lower speed rolling is observed more whereas at higher speed sliding and spinning is observed.

\section{Conclusions}

The present study investigates the performance of graphene and MWCNT nano-lubricant in terms of coefficient of friction and wear depth on a pin on disc tribometer. The tribological tests (friction and wear characteristics) were performed under dry, conventional lubricant, GnP and MWCNT mixed nanolubricants on pin-on-disc tribometer. Based on the results and discussion following conclusions are drawn:

- The addition of graphene nanoplatelets and multi-walled carbon nanotubes in conventional lubricant observed an improvement of $1.95 \%$ to $12.33 \%$ and $3.6 \%$ to $18.34 \%$ respectively in thermal conductivity for varying concentration (from 0.05 to $1.00 \mathrm{wt} \%$ ) as compared to conventional lubricant at $80^{\circ} \mathrm{C}$.

- Similarly, addition of graphene nanoplatelets and multi-walled carbon nanotubes in conventional lubricant observed an increment of $7.88 \%$ to $30.77 \%$ and $5.77 \%$ to $23.07 \%$ respectively in viscosity for varying concentration (from 0.05 to $1.00 \mathrm{wt} . \%$ ) as compared to conventional lubricant at $80{ }^{\circ} \mathrm{C}$. 
- Addition of 0.8 wt. \% concentration of GnP reduces the coefficient of friction to $58.39 \%$ at and wear rate reduces to $61.80 \%$ at sliding speed of $20 \mathrm{~m} / \mathrm{min}$ compare to pure conventional lubricants without nanoparticles.

- The addition of $0.8 \mathrm{wt}$. \% concentration of MWCNT reduces the coefficient of friction to $26.27 \%$ and wear rate reduces to $47.35 \%$ at the sliding speed of $20 \mathrm{~m} / \mathrm{min}$ when compared with pure conventional lubricants without nanoparticles.

- The GnP mixed nanolubricants performs better as compared to MWCNT mixed nanolubricants due to the difference in their structure.

- The FESEM and metallurgical microscopic image analysis noticed that the inclusion of nanoparticles gives better and smoother surface due to the formation of the thin protective layer and various lubrication mechanisms responsible for reducing the wear and coefficient of friction compared to dry and pure conventional lubricant.

- These experimental results will help the researchers/practitioners to develop a new class of lubricants for metalworking applications.

In the present study, two different morphological nanomaterials have been tested for its tribological performance. The experimental results reveal that application of nanolubricant reduces the coefficient of friction and wear. The tribological results are encouraging and this study can be used for various metal removal process, where tool, workpiece and chips are in contact with each other. However, more work is needed to be carried out to investigate the influence of different types of nanoparticle in single/hybrid nanofluid on tribological properties. Moreover, MQL operating parameters, such as flow rate, spray distance, spray nozzle orientation angle and air pressure on pin-on-disc can also be investigated

\section{References:}

Alves, S. M. et al. (2013) 'Tribological behavior of vegetable oil-based lubricants with nanoparticles of oxides in boundary lubrication conditions', Tribology International, Vol. 65, pp. 28-36.

Amiril, S. A. S., Rahim, E. A. and Syahrullail, S. (2017) 'A review on ionic liquids as sustainable lubricants in manufacturing and engineering: Recent research, performance, and applications', Journal of Cleaner Production, Vol. 168, pp. 1571-1589.

Berman, D., Erdemir, A. and Sumant, A. V. (2014) 'Graphene: A new emerging lubricant', 
Materials Today, Vol. 17, No. 1, pp. 31-42.

Chen, C. S. et al. (2005) 'Modification of multi-walled carbon nanotubes with fatty acid and their tribological properties as lubricant additive', Carbon, Vol. 43, No. 8, pp. 1660-1666.

Dai, W. et al. (2016) 'Formation of Anti-Wear Tribofilms via $\alpha$-ZrP Nanoplatelet as Lubricant Additives', Lubricants, Vol. 4, No. 3, pp. 28.

Das, P. K. et al. (2017) 'Experimental investigation of thermophysical properties of Al2O3-water nanofluid: Role of surfactants', Journal of Molecular Liquids, Vol. 237, pp. 304-312.

Ettefaghi, E. o llah et al. (2013) 'Preparation and thermal properties of oil-based nanofluid from multi-walled carbon nanotubes and engine oil as nano-lubricant', International Communications in Heat and Mass Transfer, Vol. 46, pp. 142-147.

Ezugwu, E. O., Bonney, J. and K. A. Olajire (2004) 'The effect of coolant concentration on the machinability of nickel base, nimonic C-23, alloy', Tribology Letters, Vol. 16, No. 4, pp. 311316.

Gara, L. and Zou, Q. (2013) 'Friction and wear characteristics of oil-based ZnO nanofluids', Tribology Transactions, Vol. 56, No. 2, pp. 236-244.

He, A. et al. (2017) 'Tribological Performance and Lubrication Mechanism of Alumina Nanoparticle Water-Based Suspensions in Ball-on-Three-Plate Testing', Tribology Letters, Vol. 65, No. 2, pp. 40.

Hernandez Battez, A. et al. (2006) 'The tribological behaviour of $\mathrm{ZnO}$ nanoparticles as an additive to PAO6', Wear, Vol. 261, Nos. 3-4, pp. 256-263.

$\mathrm{Hu}, \mathrm{K}$. H. et al. (2011) 'Synergistic Effect of Nano-MoS2 and Anatase Nano-TiO2 on the Lubrication Properties of MoS2/TiO2 Nano-Clusters', Tribology Letters, Vol. 43, No. 1, pp. 7787.

Huang, W. T., Liu, W. S. and Wu, D. H. (2016) 'Investigations into lubrication in grinding processes using MWCNTs nanofluids with ultrasonic-assisted dispersion', Journal of Cleaner Production, Vol. 137, pp. 1553-1559.

Ji, X. et al. (2011) 'Tribological properties of $\mathrm{CaCO} 3$ nanoparticles as an additive in lithium grease', Tribology Letters, Vol. 41, No. 1, pp. 113-119.

Kalin, M., Kogovšek, J. and Remškar, M. (2012) 'Mechanisms and improvements in the friction and wear behavior using MoS2 nanotubes as potential oil additives', Wear, 280-281, pp. 36-45. Katiyar, J. K., Sinha, S. K. and Kumar, A. (2016) 'Effects of carbon fillers on the tribological and 
mechanical properties of an epoxy-based polymer (SU-8)', Tribology-Materials, Surfaces \& Interfaces, Vol. 10, No. 1, pp. 33-44.

Krolczyk, G. M. et al. (2016) 'Dry cutting effect in turning of a duplex stainless steel as a key factor in clean production', Journal of Cleaner Production, Vol. 142, pp. 3343-3354.

Li, C. et al. (2015) 'Experimental evaluation on tribological properties of nano-particle jet MQL grinding', International Journal of Surface Science and Engineering, Vol. 9, Nos. 2-3, pp. 159175.

Liang, H. et al. (2017) 'Investigation of film formation mechanism of oil-in-water (O/W) emulsions at high speeds', Tribology International, Vol. 109, pp. 428-434.

Lin, J., Wang, L. and Chen, G. (2011) 'Modification of Graphene Platelets and their Tribological Properties as a Lubricant Additive', Tribology Letters, Vol. 41, No. 1, pp. 209-215.

Lin, Y. et al. (2015) 'Wear and friction characteristics of surface-modified aluminium alloys', International Journal of Surface Science and Engineering, Vol. 9, Nos. 2-3, pp. 109-123.

Mao, C. et al. (2014) 'The tribological properties of nanofluid used in minimum quantity lubrication grinding', International Journal of Advanced Manufacturing Technology, Vol. 71, Nos. 5-8, pp. 1221-1228.

Maruda, R. W. et al. (2015) 'An influence of active additives on the formation of selected indicators of the condition of the X10CrNi18-8 stainless steel surface layer in MQCL conditions', International Journal of Surface Science and Engineering, Vol. 9, Nos. 5, pp. 452-465.

Maruda, R. W. et al. (2017) 'Tool wear characterizations in finish turning of AISI 1045 carbon steel for MQCL conditions', Wear, Vol. 372-373, pp. 54-67.

Mehrali, M. et al. (2014) 'Investigation of thermal conductivity and rheological properties of nanofluids containing graphene nanoplatelets', Nanoscale Res Lett, Vol. 9, No. 1, pp. 1-12.

Padgurskas, J. et al. (2013) 'Tribological properties of lubricant additives of $\mathrm{Fe}, \mathrm{Cu}$ and $\mathrm{Co}$ nanoparticles', Tribology International, Vol. 60, pp. 224-232.

Padmanabhan, P. et al. (2016) 'Study the influence of case hardening and sliding wear parameters on carburised AISI 1211 steel', International Journal of Surface Science and Engineering, Vol. 10, No. 5, pp. 415-431.

Pendleton, A. et al. (2010) 'Effects of Nanostructured Additives on Boundary Lubrication for Potential Artificial Joint Applications', Journal of Tribology, Vol. 132, No. 3, p. 31201.

Peng, Y., Hu, Y. and Wang, H. (2007) 'Tribological behaviors of surfactant-functionalized carbon 
nanotubes as lubricant additive in water', Tribology Letters, Vol. 25, No. 3, pp. 247-253.

Rapoport, L., Fleischer, N. and Tenne, R. (2003) 'Fullerene-like WS2 Nanoparticles: Superior Lubricants for Harsh Conditions', Advanced Materials, Vol. 15, Nos. 7-8, pp. 651-655.

Rasheed, A. K. et al. (2016) 'Graphene based nanofluids and nanolubricants - Review of recent developments', Renewable and Sustainable Energy Reviews, Vol. 63, pp. 346-362.

Rodrigues, A. C. P. et al. (2015) 'Effect of $\mathrm{Cu}$ particles as an interfacial media addition on the friction coefficient and interface microstructure during (steel/steel) pin on disc tribotest', Wear, Vol. 330-331, pp. 70-78.

Rodrigues, A. C. P. et al. (2017) 'Impact of copper nanoparticles on tribofilm formation determined by pin-on-disc tests with powder supply: Addition of artificial third body consisting of Fe3O4, $\mathrm{Cu}$ and graphite', Tribology International, Vol. 110, pp. 103-112.

Shahnazar, S., Bagheri, S. and Abd Hamid, S. B. (2016) 'Enhancing lubricant properties by nanoparticle additives', International Journal of Hydrogen Energy, Vol. 41, No. 4, pp. 3153-3170. Sharma, A. K., Singh, R. K., et al. (2016) 'Characterization and experimental investigation of A12O3nanoparticle based cutting fluid in turning of AISI 1040 steel under minimum quantity lubrication (MQL)', Materials Today: Proceedings, Vol. 3, No. 6, pp. 1899-1906.

Sharma, A. K., Tiwari, A. K., et al. (2016) 'Tribological Investigation of TiO2 Nanoparticle based Cutting Fluid in Machining under Minimum Quantity Lubrication (MQL)', Materials Today: Proceedings, Vol. 3, No. 6, pp. 2155-2162.

Sharma, A. K. et al. (2017) 'Investigation into Performance of SiO2 Nanoparticle Based Cutting Fluid in Machining Process', Materials Today: Proceedings, Vol. 4, No. 2, pp. 133-141.

Sharma, A. K. et al. (2017) 'Novel uses of alumina-MoS $<$ inf $>2</$ inf $>$ hybrid nanoparticle enriched cutting fluid in hard turning of AISI 304 steel', Journal of Manufacturing Processes, Vol. 30, pp. 467-482.

Sharma, A. K. et al. (2018) 'Novel uses of alumina/graphene hybrid nanoparticle additives for improved tribological properties of lubricant in turning operation', Tribology International, Vol. 119, pp. 99-111.

Sharma, A. K., Tiwari, A. K. and Dixit, A. R. (2015) 'Mechanism of Nanoparticles functioning and Effects in Machining Processes: A review', Materials Today: Proceedings, Vol. 2, No. 4-5, pp. 3539-3544.

Shrivastava, A. K., Singh, K. K. and Dixit, A. R. (2017) 'Tribological properties of Al 7075 alloy 
and Al 7075 metal matrix composite reinforced with SiC, sliding under dry, oil lubricated, and inert gas environments', Proceedings of the Institution of Mechanical Engineers, Part J: Journal of Engineering Tribology, (In press), doi: 10.1177/1350650117726631.

Singh, R. K., Dixit, A. R., et al. (2017) 'Emerging application of nanoparticle-enriched cutting fluid in metal removal processes: a review', Journal of the Brazilian Society of Mechanical Sciences and Engineering, Vol. 39, No. 11, pp. 4677-4717.

Singh, R. K., Sharma, A. K., Dixit, A. R., Mandal, A., et al. (2017) 'Experimental investigation of thermal conductivity and specific heat of nanoparticles mixed cutting fluids', Materials Today: Proceedings, Vol. 4, No. 8, pp. 8587-8596.

Singh, R. K., Sharma, A. K., Dixit, A. R., Tiwari, A. K., et al. (2017) 'Performance evaluation of alumina-graphene hybrid nano-cutting fluid in hard turning', Journal of Cleaner Production, Vol. 162, pp. 830-845.

Singh, Y. et al. (2017) 'Sustainability of a non-edible vegetable oil based bio-lubricant for automotive applications: A review', Process Safety and Environmental Protection. Institution of Chemical Engineers, Vol. 111, pp. 701-713.

Taha-Tijerina, J. et al. (2013) 'Multifunctional nanofluids with 2D nanosheets for thermal and tribological management', Wear, Vol. 302, Nos. 1-2, pp. 1241-1248.

Tang, Z. and Li, S. (2014) 'A review of recent developments of friction modifiers for liquid lubricants (2007-present)', Current Opinion in Solid State and Materials Science, Vol. 18, No. 3, pp. 119-139.

Tiara, A. M. et al. (2017) 'Heat transfer enhancement using surfactant based alumina nanofluid jet from a hot steel plate', Experimental Thermal and Fluid Science, Vol. 89, pp. 295-303.

Wang, B. G. et al. (2010) 'Rheological and Tribological Properties of Ionic Liquid-Based Nanofluids Containing Functionalized Multi-Walled Carbon Nanotubes', Journal of Physical Chemistry C, Vol. 114, No. 19, pp. 8749-8754.

$\mathrm{Wu}$, H. et al. (2017) 'A study of the tribological behaviour of TiO2 nano-additive water-based lubricants', Tribology International, Vol. 109, pp. 398-408.

Wu, Y. Y., Tsui, W. C. and Liu, T. C. (2007) 'Experimental analysis of tribological properties of lubricating oils with nanoparticle additives', Wear, Vol. 262, Nos. 7-8, pp. 819-825.

Xia, W. et al. (2017) 'Effects of oil-in-water based nanolubricant containing TiO2 nanoparticles on the tribological behaviour of oxidised high-speed steel', Tribology International, Vol. 110, pp. 
77-85.

Xie, H. et al. (2016) 'An Investigation on the Tribological Performances of the SiO2/MoS2 Hybrid Nanofluids for Magnesium Alloy-Steel Contacts', Nanoscale Research Letters, Vol. 11, No. 1, p. 329.

Yang, J. et al. (2017) 'Synthesis of the liquid-like graphene with excellent tribological properties', Tribology International, Vol. 105, pp. 118-124.

Yu, B. et al. (2008) 'A novel lubricant additive based on carbon nanotubes for ionic liquids', Materials Letters, Vol. 62, Nos. 17-18, pp. 2967-2969.

$\mathrm{Yu}, \mathrm{H} .-$ L. et al. (2007) 'Tribological properties and lubricating mechanism of $\mathrm{Cu}$ nanoparticles in lubricant', Cailiao Gongcheng/Journal of Materials Engineering, (10).

Zhang, H. et al. (2017) 'Stability, thermal conductivity, and rheological properties of controlled reduced graphene oxide dispersed nanofluids', Applied Thermal Engineering, Vol. 119, pp. 132139.

Zhang, L. et al. (2014) 'Frictional dependence of graphene and carbon nanotube in diamond-like carbon/ionic liquids hybrid films in vacuum', Carbon, Vol. 80, No. 1, pp. 734-745.

Zhao, C., Chen, Y. K. and Ren, G. (2013) 'A Study of Tribological Properties of Water-Based Ceria Nanofluids', Tribology Transactions, Vol. 56, No. 2, pp. 275-283.

Zhao, J. et al. (2016) 'An investigation on the tribological properties of multilayer graphene and MoS2 nanosheets as additives used in hydraulic applications', Tribology International, 97, pp. 1420 . 